\title{
Effect of metformin in the prognosis of patients with small-cell lung cancer combined with diabetes mellitus
}

\author{
Hongyang $\mathrm{Lu}^{1,2, A, B, D}$, Fajun Xie ${ }^{2, B}$, Zhiyu Huang ${ }^{2, B}$, Jing Qine, ${ }^{2, C, E}, N_{a} H_{a n}^{2, B}$, Weimin Mao ${ }^{1, A, F}$ \\ ${ }^{1}$ Zhejiang Key Laboratory of Diagnosis and Treatment Technology on Thoracic Oncology (Lung and Esophagus), Zhejiang Cancer Hospital, Hangzhou, China \\ ${ }^{2}$ Department of Thoracic Medical Oncology, Zhejiang Cancer Hospital, Hangzhou, China \\ A - research concept and design; $B$ - collection and/or assembly of data; $C$ - data analysis and interpretation; \\ $D$ - writing the article; $E$ - critical revision of the article; $F$ - final approval of the article
}

\section{Address for correspondence}

Weimin Mao

E-mail:weiminmao@163.com

\section{Funding sources}

This work was supported by the Zhejiang Province Medical Science Fund Project of China (№. 2015ZHA006), and the 1022 Talent Training Program of Zhejiang Cancer Hospital.

Conflict of interest

None declared

Received on April 13, 2016

Reviewed on June 17, 2016

Accepted on February 16, 2017

\begin{abstract}
Background. The prognosis for small-cell lung cancer (SCLC) is very poor, so a new therapeutic strategy and new drugs are imperative.
\end{abstract}

Objectives. The aim of this study was to examine the effect of metformin on the prognosis of patients with SCLC combined with diabetes mellitus (DM).

Material and methods. From 2005 to 2013, 32 patients (4 female and 28 male) with SCLC combined with DM were included in this retrospective study at the Zhejiang Cancer Hospital, Hangzhou, China. All patients were diagnosed with SCLC by pathological analysis and had received more than 4 cycles of chemotherapy. Metformin was used in 12 patients. Seventeen patients had limited-stage disease (LD) and 15 patients had extensive-stage disease (ED). Patients with LD SCLC were administered thoracic radiotherapy. The follow-up deadline was January 27, 2016. At that point, 4 patients were alive, 21 patients had died, and 7 patients did not participate in follow-up examinations.

Results. In patients with SCLC combined with DM using metformin, a complete response (CR) was observed in 4 patients, a partial response (PR) in 6 patients, a stable disease (SD) in 1 patient, and a progressive disease (PD) in 1 patient, whereas in patients who did not use metformin, (R was observed in 2 patients, PR in $15 \mathrm{pa}$ tients, SD in 2 patients, and PD in 1 patient $(p=0.384)$. There was no difference in the median survival time (MST) between patients using metformin and those who did not (12 vs 13 months; $p=0.784$ ). There was a trend toward prolonged MST in patients with LD SCLC using metformin compared with those who did not use metformin (58 vs 29 months; $p=0.084$ ). There was no difference due to the use of metformin observed in MST of patients with ED SCLC (12 vs 13 months; $p=0.396)$.

Conclusions. Metformin use may have a prognostic benefit in patients with SCLC combined with DM. This combination is promising and further clinical trials are required.

Key words: small-cell lung cancer, diabetes mellitus, metformin, prognosis

DOI

10.17219/acem/69021

Copyright

Copyright by Author(s)

This is an article distributed under the terms of the

Creative Commons Attribution Non-Commercial License

(http://creativecommons.org/licenses/by-nc-nd/4.0/) 
Lung cancer is the leading cause of cancer-related mortality and the most common malignancy in the world. ${ }^{1}$ The data from the National Central Cancer Registry of China indicated that an estimated 4,292,000 new patients with cancer and 2,814,000 cancer-related deaths would occur in China in 2015, and that lung cancer is the leading cause of cancer death. ${ }^{2}$ Lung cancer includes smallcell lung cancer (SCLC) and non-small cell lung cancer (NSCLC). The proportion of SCLC among all histological types of lung cancer decreased from 17.26 in 1986 to 12.95 in $2002 .^{3}$ The prognosis of SCLC is very poor, and a new therapeutic strategy and new drugs are imperative.

Metformin is the preferred drug for starting treatment of diabetes mellitus (DM), and it has been reported to have a potential anticancer effect on some solid tumors, such as lung, hepatocellular, and melanoma. ${ }^{4-6}$ Metformin might be used in combination with tyrosine kinase inhibitors (TKIs) in patients with NSCLC, harboring mutations in epidermal growth factor receptor to overcome resistance to TKI and to prolong the survival time of patients. ${ }^{7}$ Metformin and gefitinib are synergistic in LKB1 wild-type NSCLC cells, ${ }^{8}$ and metformin has the ability to partially block the M2-like polarization of macrophages through the adenosine monophosphate-activated protein kinase $\alpha 1$ pathway, which plays an important role in metformininhibited metastasis of Lewis lung cancer. ${ }^{9}$ Metformin as a monotherapy reduces the metabolic viability of SCLC in the NCI-H460 cell line. Combining metformin with cisplatin or etoposide produced a synergistic effect and is more effective than the use of cisplatin or etoposide as a monotherapy in the NCI-H460 cell line. ${ }^{10}$ At the time of diagnosis of SCLC, DM did not have prognostic importance for the survival of patients. ${ }^{11}$ Metformin use may be associated with a good prognosis in patients with lung cancer combined with DM, but the effect was modest. However, it could achieve benefits in a selective sub-group of patients with lung cancer, especially in patients with SCLC from Asia. ${ }^{12}$

This study aimed to further elucidate the effect of metformin treatment in combination with chemotherapy in patients with SCLC combined with DM. A total of 32 patients with SCLC combined with DM were included in this study. The clinical parameters and survival data were collected and analyzed.

\section{Material and methods}

\section{Patient characteristics}

From 2005 to 2013, 32 patients (4 female and 28 male) with SCLC combined with DM were included in this retrospective study at the Zhejiang Cancer Hospital, China. All patients were diagnosed with SCLC by pathological analysis based on the standard criteria defined by the World Health Organization classification and they had received more than 4 cycles of chemotherapy. The stages of the Veterans Administration Lung Study Group (VALSG) included limited-stage disease (LD) in 17 patients and extensive-stage disease (ED) in 15 patients. Fifteen patients with LD SCLC received thoracic radiotherapy. The mean age of patients was 62 years (range: $48-75$ years). Five patients were non-smokers, 2 patients were light smokers, 25 patients were heavy smokers, and there were 0 moderate smokers. The median value for smoking history was 40 pack-years. Metformin was used in 12 patients. There were no significant differences in age, smoking history, or disease stage between the patients with SCLC using metformin and those not using metformin ( $p>0.05)$, whereas there was a difference in $\operatorname{sex}(\mathrm{p}=0.015)$ (Table 1$)$. There were no significant differences in age, sex, smoking history, or disease stage between the patients using metformin and those not using metformin in either subgroup of patients - with LD and ED SCLC ( $>$ > 0.05) (Tables 2, 3).

Table 1. Clinical features of patients with SCLC using metformin or not

\begin{tabular}{|l|c|c|c|}
\multicolumn{1}{|c|}{ Characteristics } & Metformin & $\begin{array}{r}\text { Without } \\
\text { metformin }\end{array}$ & p-value \\
\hline Number of patients $(n=32)$ & 12 & 20 & - \\
\hline Age (median) & $60(48-73)$ & $62.5(51-75)$ & 0.29 \\
\hline $\begin{array}{l}\text { Sex (female/male) } \\
\text { Smoking history } \\
\text { (median pack-years) }\end{array}$ & $0 / 12$ & $4 / 16$ & 0.015 \\
\hline Stage (LD/ED) & $35(4-120)$ & $40(0-120)$ & 0.27 \\
\hline
\end{tabular}

SCLC - small-cell lung cancer; LD - limited-stage disease; ED - extensivestage disease.

Table 2. Clinical features of patients with LD SCLC using metformin or not

\begin{tabular}{|l|c|c|c|}
\hline \multicolumn{1}{|c|}{ Characteristics } & Metformin & $\begin{array}{c}\text { Without } \\
\text { metformin }\end{array}$ & $p$-value \\
\hline Number of patients $(n=17)$ & 6 & 11 & - \\
\hline Age (median) & $60(54-65)$ & $60.5(48-73)$ & 0.79 \\
\hline $\begin{array}{l}\text { Sex (female/male) } \\
\text { Smoking history } \\
\text { (median pack-years) }\end{array}$ & $0 / 6$ & $3 / 8$ & 0.159 \\
\hline
\end{tabular}

LD SCLC - limited-stage disease small-cell lung cancer.

Table 3. Clinical features of patients with ED SCLC using metformin or not

\begin{tabular}{|l|c|c|c|}
\hline \multicolumn{1}{|c|}{ Characteristics } & Metformin & $\begin{array}{r}\text { Without } \\
\text { metformin }\end{array}$ & p-value \\
\hline Number of patients $(n=15)$ & 6 & 9 & - \\
\hline Age (median) & $62.5(48-73)$ & $68(52-75)$ & 0.22 \\
\hline $\begin{array}{l}\text { Sex (female/male) } \\
\text { Smoking history } \\
\text { (median pack-years) }\end{array}$ & $0 / 6$ & $1 / 8$ & 0.398 \\
\hline
\end{tabular}

ED SCLC - extensive-stage disease small-cell lung cancer. 


\section{Follow-up}

The follow-up deadline was January 27, 2016. At that point, 4 patients were alive, 21 patients had died, and 7 patients did not participate in follow-up examinations. The survival time was calculated from the date of pathological diagnosis.

\section{Statistical analysis}

The data was analyzed using the statistical package for the social sciences software v. 15.0. Overall data was screened using the $\chi^{2}$ test, and survival time was calculated using Kaplan-Meier software with a statistical significance of $\mathrm{p}<0.05$.

\section{Results}

In patients with SCLC combined with DM using metformin, a complete response (CR) was observed in 4 patients, a partial response (PR) in 6 patients, a stable disease (SD) in 1 patient, and a progressive disease (PD) in 1 patient, whereas in patients not using metformin, CR was observed in 2 patients, PR in 15 patients, SD in 2 patients, and PD in 1 patient $(\mathrm{p}=0.384)$. There was no significant difference in the median survival time (MST) between patients using metformin and those not using metformin (12 vs 13 months; $\mathrm{p}=0.784$ ) (Fig. 1 ). In patients with LD SCLC combined with DM using metformin, CR was observed in 4 patients, PR in 2 patients, SD in 0 patients, and PD

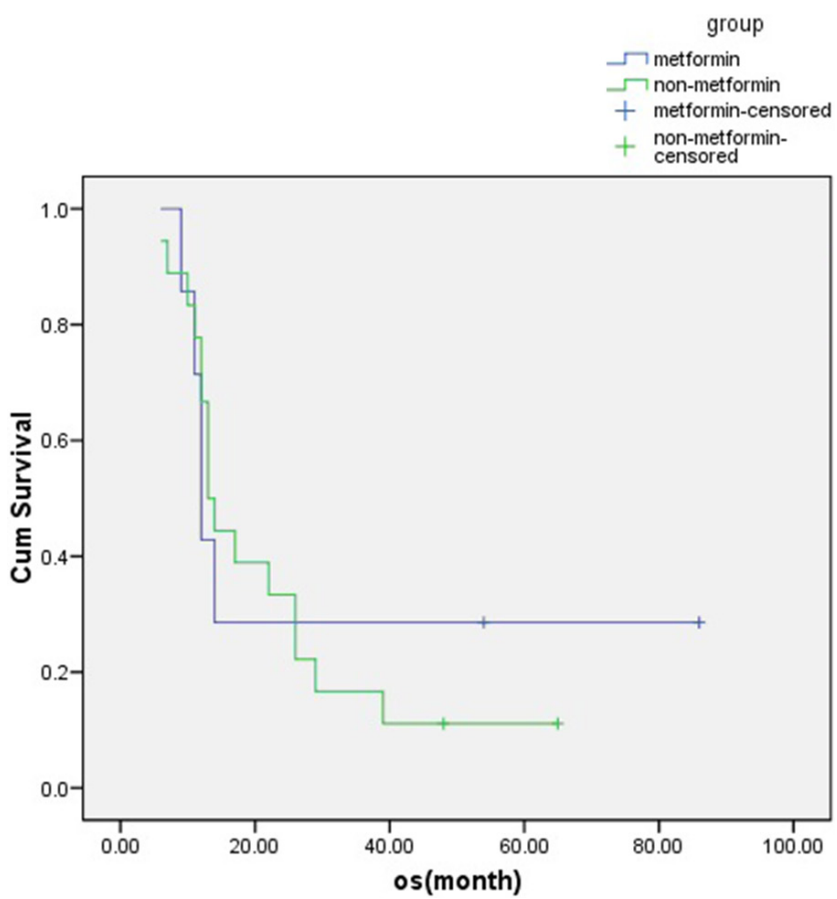

Fig. 1. The survival time of patients with SCLC combined with DM using metformin or not $(n=32)$

SCLC - small-cell lung cancer; DM - diabetes mellitus.

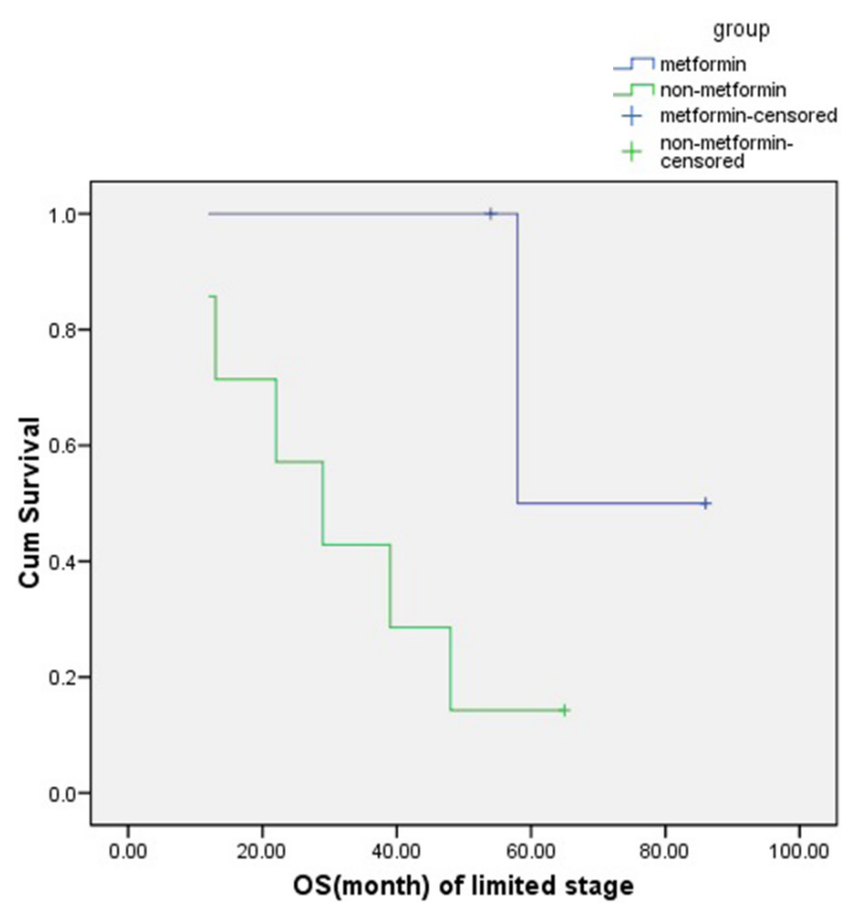

Fig. 2. The survival time of patients with LD SCLC combined with DM using metformin or not $(n=17)$

LD SCLC - limited-stage disease small-cell lung cancer; DM - diabetes mellitus.

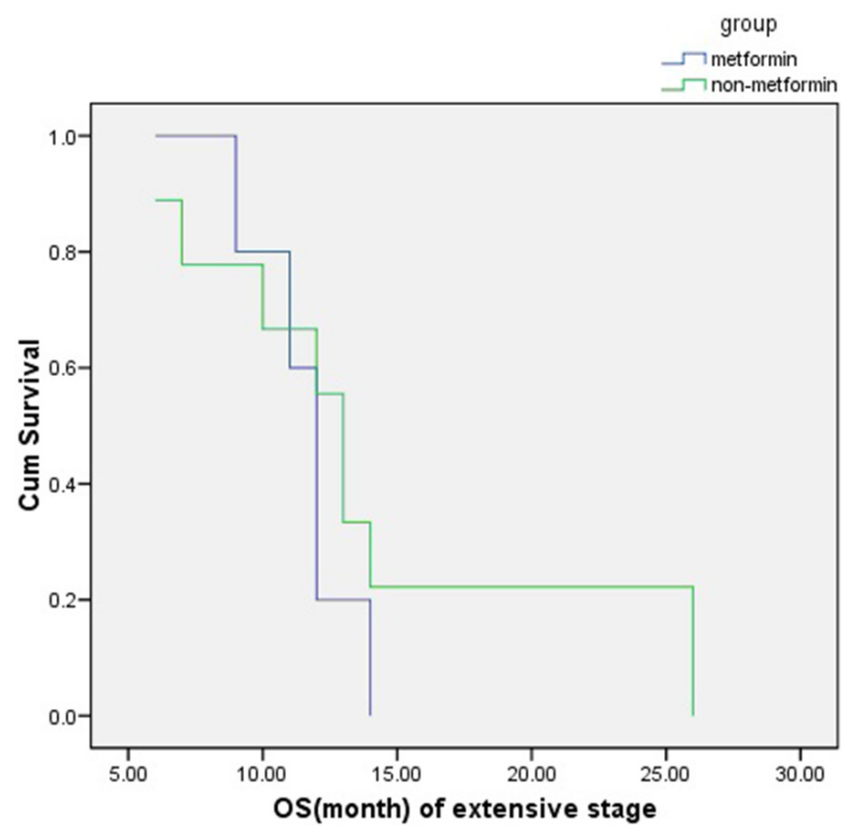

Fig. 3. The survival time of patients with ED SCLC combined with DM using metformin or not $(n=15)$

ED SCLC - extensive-stage disease small-cell lung cancer; DM - diabetes mellitus.

in 0 patients, whereas in patients not using metformin, CR was observed in 2 patients, a PR in 8 patients, SD in 1 patient, and PD in 0 patients $(\mathrm{p}=0.125)$. There was a trend toward prolonged MST in patients with LD SCLC using metformin compared to those not using metformin (58 vs 29 months; $\mathrm{p}=0.084$ ) (Fig. 2). In patients with ED SCLC 
combined with DM using metformin, CR was observed in 0 patients, $P R$ in 4 patients, SD in 1 patient, and $P D$ in 1 patient, whereas in patients not using metformin, CR was observed in 0 patients, PR in 7 patients, SD in 2 patients, and PD in 1 patient ( $\mathrm{p}=0.446$ ). There was no difference in MST between patients with ED SCLC using metformin and those not using metformin (12 vs 13 months; $\mathrm{p}=0.396)$ (Fig. 3).

\section{Discussion}

Patients with SCLC are commonly classified as LD or ED by the VALSG staging system. Chemotherapy is the cornerstone of the treatment; however, 4 to 6 cycles of chemotherapy are needed for patients with ED or LD SCLC. The standard clinical practice in LD SCLC is to combine chemotherapy and thoracic radiotherapy (TRT). In this study, all patients had received more than 4 cycles of chemotherapy, and patients with LD SCLC additionally received TRT. A response to combination chemotherapy can be achieved by $80-90 \%$ of patients with LD SCLC and their MST is 15-20 months, with or without TRT. ${ }^{13-14}$ Of all the patients with ED SCLC, 60-80\% respond to chemotherapy and their MST is $8-12$ months. ${ }^{15-17}$ The most commonly used initial combination chemotherapy regimens are etoposide combined with cisplatin (EP) and etoposide combined with carboplatin (EC). Several studies have shown a similar effect with chemotherapy regimens of irinotecan combined with cisplatin and irinotecan combined with carboplatin in ED SCLC compared to EP or EC. ${ }^{15-17}$ Despite trends toward a modest improvement in survival of SCLC, the prognosis is extremely poor. Certain newly-targeted agents offer a promise of improved outcomes, but no targeted drugs have been recommended by the National Comprehensive Cancer Network guideline for SCLC. ${ }^{18}$ It is imperative to seek new drugs to improve the survival time of patients. The use of metformin improved the long-term outcome of patients with SCLC combined with DM, which might be considered a potential useful prognostic indicator and anticancer drug. ${ }^{19}$ There are few studies about the effect of metformin use in patients with SCLC combined with DM, and it needs to be further evaluated and confirmed, especially in China.

Disease stage and sex were identified as important prognostic factors, but not DM. ${ }^{11,20}$ There is a significant difference in sex between the patients who used metformin and those who did not, whereas there was no significant difference between the patients with LD SCLC or ED SCLC who used metformin and those who did not. There were no significant differences in age, disease stage, or smoking history between patients using metformin and those not using it. Wheatley-Price et al. reported that data from over 1,700 patients with SCLC in randomized chemotherapy trials confirmed that women survive slightly longer than men. ${ }^{20}$ The results have shown that there was no significant difference in MST between all patients with SCLC, using metformin and not. Due to the higher number of female patients with SCLC not using metformin, there may be no difference in MST between the groups. There was a trend toward prolonged MST in patients with LD SCLC using metformin compared to those not using it, and there was no significant difference in sex. Metformin use may have a prognosis benefit in patients with SCLC combined with DM based on the results of this study and that of Kong et al. ${ }^{19}$ Considering the limited number of patients in this study, however, the results need to be validated on a larger sample of patients, probably in a multicenter prospective study. More studies need to be carried out in order to clarify the mechanism of the synergistic effect of metformin and chemotherapy/radiotherapy, though this combination is promising.

\section{References}

1. Siegel R, Naishadham D, Jemal A. Cancer statistics, 2013. CA Cancer J Clin. 2013;63:11-30.

2. Chen W, Zheng R, Baade PD, et al. Cancer statistics in China, 2015. CA Cancer J Clin. 2016. doi: 10.3322/caac.21338

3. Govindan R, Page N, Morgensztern D, et al. Changing epidemiology of small-cell lung cancer in the United States over the last 30 years: Analysis of the surveillance, epidemiologic, and end results database. J Clin Oncol. 2006;24:4539-4544.

4. Leone A, Di Gennaro E, Bruzzese F, Avallone A, Budillon A. New perspective for an old antidiabetic drug: Metformin as anticancer agent. Cancer Treat Res. 2014;159:355-376.

5. Guo Z, Cao M, You A, et al. Metformin inhibits the pro-metastatic effect of sorafenib in hepatocellular carcinoma by upregulating the expression of TIP30. Cancer Sci. 2016. doi: 10.1111/cas.12885

6. Liang G, Ding M, Lu H, et al. Metformin upregulates E-cadherin and inhibits B16F10 cell motility, invasion and migration. Oncol Lett. 2015;10:1527-1532.

7. Li L, Han R, Xiao H, et al. Metformin sensitizes EGFR-TKI-resistant human lung cancer cells in vitro and in vivo through inhibition of IL-6 signaling and EMT reversal. Clin Cancer Res. 2014;20:2714-2726.

8. Morgillo F, Sasso FC, Della Corte CM, et al. Synergistic effects of metformin treatment in combination with gefitinib, a selective EGFR tyrosine kinase inhibitor, in LKB1 wild-type NSCLC cell lines. Clin Cancer Res. 2013;19:3508-3519.

9. Ding L, Liang G, Yao Z, et al. Metformin prevents cancer metastasis by inhibiting M2-like polarization of tumor associated macrophages. Oncotarget. 2015;6:36441-36455.

10. Teixeira SF, Guimarães Idos S, Madeira KP, Daltoé RD, Silva IV, Rangel LB. Metformin synergistically enhances antiproliferative effects of cisplatin and etoposide in $\mathrm{NCl}-\mathrm{H} 460$ human lung cancer cells. J Bras Pneumol. 2013;39:644-649.

11. Inal A, Kaplan MA, Kucukoner M, et al. Is diabetes mellitus a prognostic factor for survival in patients with small cell lung cancer? Asian Pac J Cancer Prev. 2012;13:1491-1494.

12. Tian RH, Zhang YG, Wu Z, Liu X, Yang JW, Ji HL. Effects of metformin on survival outcomes of lung cancer patients with type 2 diabetes mellitus: A meta-analysis. Clin Transl Oncol. Epub 2015 Oct 12.

13. Takada M, Fukuoka M, Kawahara M, et al. Phase III study of concurrent versus sequential thoracic radiotherapy in combination with cisplatin and etoposide for limited-stage small-cell lung cancer: Results of the Japan Clinical Oncology Group Study 9104. J Clin Oncol. 2002;20:3054-3060.

14. Sun JM, Ahn YC, Choi EK, et al. Phase III trial of concurrent thoracic radiotherapy with either first- or third-cycle chemotherapy for limited-disease small-cell lung cancer. Ann Oncol. 2013;24:2088-2092.

15. Zatloukal P, Cardenal F, Szczesna A, et al. A multicenter international randomized phase III study comparing cisplatin in combination with irinotecan or etoposide in previously untreated small-cell lung cancer patients with extensive disease. Ann Oncol. 2010;21:1810-1816. 
16. Lara PN Jr, Natale R, Crowley J, et al. Phase III trial of irinotecan/cisplatin compared with etoposide/cisplatin in extensive-stage smallcell lung cancer: Clinical and pharmacogenomic results from SWOG S0124. J Clin Oncol. 2009;27:2530-2535.

17. Hermes $A$, Bergman $B$, Bremnes $R$, et al. Irinotecan plus carboplatin versus oral etoposide plus carboplatin in extensive small-cell lung cancer: A randomized phase III trial. J Clin Oncol. 2008;26:4261-4267.

18. Lu HY, Wang XJ, Mao WM. Targeted therapies in small cell lung cancer (Review). Oncol Lett. 2013;5:3-11.
19. Kong F, Gao F, Liu H, et al. Metformin use improves the survival of diabetic combined small-cell lung cancer patients. Tumour Biol. 2015;36: 8101-8106.

20. Wheatley-Price $P, M a C$, Ashcroft LF, et al. The strength of female sex as a prognostic factor in small-cell lung cancer: A pooled analysis of chemotherapy trials from the Manchester Lung Group and Medical Research Council Clinical Trials Unit. Ann Oncol. 2010;21:232-237. 